\title{
Understanding the Soil Microfabric of Drying Mature Fine Tails
}

\author{
G. R. D. Elliott, V. A. Munoz*, J. A. Elias*, and R. J. Mikula* \\ *CanmetENERGY, Devon Research Centre, Natural Resources Canada, 1 Oil Patch \\ Drive, Devon, Alberta, Canada, T9G 1A8
}

The process of extracting bitumen from oil sands in surface mined operations in Northern Alberta creates a large amount of mine tailings. These tailings are composed of sand, silt, clays, and residual bitumen that have to be contained in large tailings pond. After 3-5 years, this material consolidates in the bottom of large recycle water ponds forming mature fine tailings. Mature fine tails are 35 to $40 \%$ solids by weight and composed of clays and silts. Because MFT has relatively low solids content, a significant portion of the make up water for the extraction process comes from the Athabasca River. This water loss is due to the accumulation of water within the MFT. In order to increase the proportion of water recycled and reused, and therefore decrease water withdrawal from the Athabasca River, a variety of tailings treatment options have been tested and commercialized.

Currently, there are four tailings treatment technologies that include consolidated tailings, rim ditching, thin lift dewatering and centrifugation. All of these treatments require a chemical modification to the clay structure in order to optimize dewatering rates. There are different states of drying that the MFT must go through before it gains enough strength to allow for reclamation of the original forest cover. As the MFT dries, it must retain the water channel network so that water may drain efficiently. These channels, pore spaces, or microfabric can be the limiting factor of drainage of the drying MFT as force of capillary suction increases preventing the water from draining. Recently, high molecular weight polymers have been used to create a soil microfabric conducive to drainage by creating large water channels and maintaining an open network the MFT dries. Polymers allow the formation of large floces that create voids or channels for dewatering of the material to occur, but polymer efficiency depends heavily upon a narrow window of optimal mixing conditions.

Correlative confocal and cryo-scanning electron imaging will be used to investigate the effect inorganic additives have on the soil microfabric of drying MFT. Inorganic additives to be evaluated include calcium and magnesium salts, alum, gypsum, lime, coke fines, clay overburden, and fly ash residues. The aim of this study is to understand interaction of the inorganic additives and polymers have on soil microfabric as it dries to allow maximal dewatering of the MFT. 